\title{
Arthur Lindo Patterson, his function and element preferences in early crystal structures
}

\author{
Carl H. Schwalbe ${ }^{a b}$ \\ ${ }^{a}$ School of Life and Health Sciences, Aston University, Aston Triangle, Birmingham B4 \\ 7ET, UK \\ ${ }^{b}$ Cambridge Crystallographic Data Centre, 12 Union Road, Cambridge CB2 1EZ, UK
}

Correspondence to: carlschwalbe@hotmail.com

Carl H. Schwalbe received his AB in Chemistry from Oberlin College and his AM from Harvard University. His PhD research at Harvard was supervised by Nobel laureate William N. Lipscomb. After postdoctoral research at the Max Planck Institute for Experimental Medicine in Göttingen, Germany, he joined Aston University in Birmingham in 1972 as a Lecturer in Pharmacy, eventually becoming Professor of Medicinal Chemistry. On retiring in 2010, he was appointed Honorary Senior Research Fellow at the Cambridge Crystallographic Data Centre. His research interests involve the use of structural information, mainly obtained by X-ray crystallography, to explain the activity of drugs and the properties of solid dosage forms. In periods of sabbatical leave at Brookhaven National Laboratory and Oxford University, he also applied neutron diffraction and computational chemistry. He has authored or co-authored three reviews on historical aspects of crystallography: the important pioneering crystallographic research done by Lars Vegard, renowned as a physicist studying the aurora borealis but little-known as a crystallographer; the identification by June Sutor of $\mathrm{C}-\mathrm{H}$... O hydrogen bonding, which met with disdain before eventually being confirmed; and the scientific and personal relationship between Max von Laue and the Braggs. 


\section{Arthur Lindo Patterson, his function and element preferences in early crystal structures}

In 1934 Arthur Lindo Patterson showed that a map of interatomic vectors is obtainable from measured X-ray diffraction data without phase information. Such maps were interpretable for simple crystal structures, but proliferation and overlapping of peaks caused confusion as the number of atoms increased. Since the peak height of a vector between two particular atoms is related to the product of their atomic numbers, a complicated structure could effectively be reduced to a simple one by including just a few "heavy" atoms (of high atomic number) since their interatomic vectors would stand out from the general clutter. Once located, these atoms provide approximate phases for Fourier syntheses that reveal the locations of additional atoms. Surveys of small-molecule structures in the Cambridge Structural Database during the periods 1936-1969, when Patterson methods were commonly used, and 1980-2013, dominated by direct methods, demonstrate large differences in the abundance of certain elements. The "moderately heavy" elements $\mathrm{K}, \mathrm{Rb}$, As and $\mathrm{Br}$ are the heaviest element in the structure more than 3 times as often in the early period than in the recent period. Examples are given of three triumphs of the heavy atom method and two initial failures that had to be overcome.Keywords: A L Patterson; Patterson function; heavy atom method; element abundance; Cambridge Structural Database

\section{Introduction}

As we celebrate the brilliant development of X-ray crystallography a century ago, we should also remember an extremely important advance that was made 80 years ago. During the first two decades of X-ray crystallography, finding a trial structure required a supremely talented scientist to come up with an inspired guess. Such was the case with William Lawrence Bragg and alkali metal halides [1], and also with Kathleen Lonsdale and hexamethylbenzene [2]. The publication of the Patterson function [3] in 1934 made it possible for the first time to obtain a trial structure by a systematic procedure that many more crystallographers could apply.

Arthur Lindo Patterson [3] was born in New Zealand on July 23, 1902. His career had superficial similarities to that of W. L. Bragg. While Patterson was a child, 
his family left the Antipodes. In Patterson's case the destination was Montreal, Canada. There he obtained bachelor's and master's degrees in physics from the local intellectual powerhouse, McGill University. Obtaining his $\mathrm{PhD}$ also from McGill might have implied insularity, but study abroad during this time gave him the essential background for his future work. He gained experience in X-ray diffraction during two years spent in William Henry Bragg's laboratory at the Royal Institution, where he determined the unit cells and space groups of a series of phenylaliphatic acids. Then he carried out research for a year at the Kaiser-Wilhelm-Institut in Berlin, applying X-ray methods to determine the particle size of cellulose samples. Work on the theory of particle-size line broadening developed his interest in Fourier transformation, which he later described as an obsession. He also had many friendly discussions with Max von Laue. After receiving his $\mathrm{PhD}$ from McGill, Patterson worked in New York and Philadelphia before spending three years starting in 1933 as a guest of John C. Slater and Bertram E. Warren in the laboratories at M. I. T. There he had many discussions about Fourier theory with the eminent mathematician Norbert Wiener. At that time he perfected the insight that led to his great breakthrough.

The electron density in the unit cell of a crystal is related to the structure factors by a Fourier summation

$$
\rho(x, y, z)=\frac{1}{V} \sum_{h k l} F_{h k l} \exp [-2 \pi i(h x+k y+l z)]
$$

where $\rho$ is the electron density at point $x, y, z$ and the structure factor $F_{h k l}$ for the reflection with Miller indices $h, k, l$ has a phase. Notoriously, the phases cannot be measured by conventional techniques; and therefore it is not possible to proceed straightaway from measured data to a crystal structure. Patterson [4] circumvented this difficulty by applying the Fourier transformation to the squared structure factors with all phases set to zero:

$$
P(u, v, w)=\frac{1}{V} \sum_{h k l}\left|F_{h k l}\right|^{2} \cos [2 \pi(h u+k v+l w)]
$$

The resulting map in $u, v, w$ space shows the vectors between atoms in the crystal structure, weighted by the product of the number of electrons in each of the atoms. Because Patterson was eager to demonstrate the practical usefulness of his new 
function, already in his original paper [4] he used published structure factor data to calculate and display vector maps in projection for two important structures, potassium dihydrogen phosphate [5] and hexachlorobenzene [6]. Features in the maps could be related to the underlying structures. In a book review [7] David Harker quoted the statement on one of the title pages that already in 1921 Paul Peter Ewald had pointed out the relationship between the squared magnitudes of the structure amplitudes and the interatomic vectors, but no one had thought to make use of it before Patterson rediscovered it.

By causing peaks to overlap, two problems impede the interpretation of a Patterson map. A structure with $N$ atoms in the unit cell will give rise to $N(N-1)+1$ vectors, each atom providing vectors to the other $(\mathrm{N}-1)$ atoms as well as a vector of zero length to itself which piles up at the origin. Because the Patterson unit cell in $u, v, w$ space is the same size as the crystallographic unit cell in $x, y, z$ space, a vector map is more crowded than the corresponding electron density map. Furthermore, because electron density peaks have finite width, the peaks for vectors between them are even broader. An additional annoyance is the enormous size of the origin peak compared to all other peaks. Patterson quickly addressed these issues. The next year he introduced a technique [8] for sharpening the peaks by compensating for thermal motion, and he showed how to remove the origin peak and, if desired, peaks between already known atoms. Subsequently Harker used space group symmetry as an aid to calculating atomic positions [9]. For instance, in the popular space group $\mathrm{P} 2{ }_{1} / \mathrm{c}$ a glide plane relates an atom at $x, y, z$ to its counterpart at $x, 0.5-y, 0.5+z$, and a screw axis generates an identical atom at $-x, 0.5+y, 0.5-z$. The vectors relating the original positions to the new positions are $0,0.5-2 y, 0.5$ and $-2 x, 0.5,0.5-2 z$ (and the same with all signs reversed). Thus by looking at lines and planes (Harker sections) with specific values of $u, v$ or $w$ one can determine values of $x, y$, or $z$ for that particular atom. The Harker plane corresponding to a screw axis is particularly useful since its peaks are spread out over a plane, not concentrated on a line, and it provides information about coordinates along two axes. In $\mathrm{P} 2{ }_{1} / \mathrm{c}$, which also has an inversion centre, checking for Patterson peaks at $2 x, 2 y, 2 z$ can confirm the correctness of these coordinates.

Despite these advances, nothing could stop the proliferation of vectors as the number of atoms increased. Only if a few atoms were "heavier" (i.e. had more electrons) than all others could certain key vectors (those between "heavy" atoms) be 
distinguished since peak height is approximately proportional to the product of the number of electrons in the participating atoms. In such cases the structure determination could proceed in manageable steps, by first working out the positions of the heavy atoms from those vectors and afterwards finding the remaining atoms.

Though convenient, the heavy atom method is not absolutely necessary to solve a complex small-molecule structure. Since a Patterson map contains multiple images of the structure, superposition of multiple copies of the map shifted by an interatomic vector can bring out one or just a few copies of the image. Points falling together in the superposition can be combined in various ways, but the most useful is to apply the minimum function [10] since much of the clutter of peaks is suppressed. Although already in 1939 the brilliant but controversial Dorothy Wrinch had demonstrated mathematically for a point intensity set the possibility of recovering the underlying structure from a vector map [11, 12], practical application did not become frequent until the 1950s. Increasingly sophisticated methods for seeking the image of a known fragment and superimposing Patterson maps to reveal a single image of the structure were developed subsequently and implemented in computer programs. Nevertheless, the inclusion of heavy atoms in the crystalline compound remained a standard technique. The heyday of Patterson methods to determine small-molecule structures can be said to run from 1936, when the first structures were published that now appear in the Cambridge Structural Database (CSD) [13] with 3D coordinates, until 1970, when MULTAN [14] provided a way to obtain phases by direct methods that was not just reliable and effective but also user-friendly. Although groups that had a great investment of experience, software, and, probably, emotional involvement continued to use Patterson techniques for a while, the rise of direct methods for solving standard organic structures was irresistible. By comparing the entries in the CSD from the period 1936-1969 with those from the period of equivalent length 1980-2013 when direct methods were dominant, this review will demonstrate the apparent selection pressure in favour of heavy atoms during the first period and identify the elements that were preferred.

\section{Results and Discussion}

\subsection{Frequency of occurrence of elements}


Version 5.35 (November 2013, updated in March 2014) of the Cambridge Structural Database [13] was searched for the presence of common elements during the periods 1936-1969 ("early") and 1980-2013 ("recent"). Totals of 3677 and 628,360 entries were found for the two periods, subject only to the requirement that $3 \mathrm{D}$ coordinates had to be determined. The results are presented in Table 1.

Table 1. Number of Cambridge Structural Database entries with 3D coordinates containing the indicated element, followed by the percentage of total entries, during 1936-1969 (above) and 1980-2013 (below). 


\begin{tabular}{|c|c|c|c|c|c|c|c|}
\hline $\mathrm{Na}$ & $\mathrm{Mg}$ & & $\mathrm{Al}$ & $\mathrm{Si}$ & $\mathrm{P}$ & $\mathrm{S}$ & $\mathrm{Cl}$ \\
\hline $\begin{array}{l}57 \\
1.55 \%\end{array}$ & $\begin{array}{l}14 \\
0.38 \%\end{array}$ & & $\begin{array}{l}26 \\
0.71 \%\end{array}$ & $\begin{array}{l}35 \\
0.95 \%\end{array}$ & $\begin{array}{l}255 \\
6.94 \%\end{array}$ & $\begin{array}{l}558 \\
15.18 \%\end{array}$ & $\begin{array}{l}697 \\
18.96 \%\end{array}$ \\
\hline $\begin{array}{l}7420 \\
1.18 \%\end{array}$ & $\begin{array}{l}2810 \\
0.45 \%\end{array}$ & & $\begin{array}{l}6655 \\
1.06 \%\end{array}$ & $\begin{array}{l}34104 \\
5.43 \%\end{array}$ & $\begin{array}{l}114045 \\
18.15 \%\end{array}$ & $\begin{array}{l}128504 \\
20.45 \%\end{array}$ & $\begin{array}{l}146018 \\
23.24 \%\end{array}$ \\
\hline $\mathrm{K}$ & $\mathrm{Ca}$ & Sc--Zn & $\mathrm{Ga}$ & $\mathrm{Ge}$ & As & $\mathrm{Se}$ & $\mathrm{Br}$ \\
\hline $\begin{array}{l}80 \\
2.18 \%\end{array}$ & $\begin{array}{l}19 \\
0.52 \%\end{array}$ & $\begin{array}{l}746 \\
20.29 \%\end{array}$ & $\begin{array}{l} \\
0.05 \%\end{array}$ & $\begin{array}{l}12 \\
0.33 \%\end{array}$ & $\begin{array}{l}63 \\
1.71 \%\end{array}$ & $\begin{array}{l}46 \\
1.25 \%\end{array}$ & $\begin{array}{l}482 \\
13.11 \%\end{array}$ \\
\hline $\begin{array}{l}6677 \\
1.06 \%\end{array}$ & $\begin{array}{l}1992 \\
0.32 \%\end{array}$ & $\begin{array}{l}177614 \\
28.27 \%\end{array}$ & $\begin{array}{l}3946 \\
0.63 \%\end{array}$ & $\begin{array}{l}3902 \\
0.62 \%\end{array}$ & $\begin{array}{l}4730 \\
0.75 \%\end{array}$ & $\begin{array}{l}8891 \\
1.41 \%\end{array}$ & $\begin{array}{l}33297 \\
5.30 \%\end{array}$ \\
\hline $\mathrm{Rb}$ & $\mathrm{Sr}$ & Y--Cd & In & $\mathrm{Sn}$ & $\mathrm{Sb}$ & $\mathrm{Te}$ & I \\
\hline $\begin{array}{l}24 \\
0.65 \%\end{array}$ & $\begin{array}{l}8 \\
0.22 \%\end{array}$ & $\begin{array}{l}196 \\
5.33 \%\end{array}$ & $\begin{array}{l} \\
0.05 \%\end{array}$ & $\begin{array}{l}32 \\
0.87 \%\end{array}$ & $\begin{array}{l}25 \\
0.68 \%\end{array}$ & $\begin{array}{l}6 \\
0.71 \%\end{array}$ & $\begin{array}{l}191 \\
5.19 \%\end{array}$ \\
\hline $\begin{array}{l}782 \\
0.12 \%\end{array}$ & $\begin{array}{l}1001 \\
0.16 \%\end{array}$ & $\begin{array}{l}96024 \\
15.28 \%\end{array}$ & $\begin{array}{l}2370 \\
0.38 \%\end{array}$ & $\begin{array}{l}10701 \\
1.70 \%\end{array}$ & $\begin{array}{l}5554 \\
0.88 \%\end{array}$ & $\begin{array}{l}3581 \\
0.57 \%\end{array}$ & $\begin{array}{l}19814 \\
3.15 \%\end{array}$ \\
\hline Cs & $\mathrm{Ba}$ & & & & & & \\
\hline $\begin{array}{l}16 \\
0.44 \%\end{array}$ & $\begin{array}{l}6 \\
0.16 \%\end{array}$ & & & & & & \\
\hline $\begin{array}{l}1228 \\
0.20 \%\end{array}$ & $\begin{array}{l}1494 \\
0.24 \%\end{array}$ & & & & & & \\
\hline
\end{tabular}

It can be seen that there are significant differences in relative abundance of elements between early and recent years, particularly among the alkali metals and halogens.

Figures 1-3 show that there are sizeable differences between rows of the Periodic Table. 
While, with the lone exception of sodium, Period 3 elements occur more frequently in recent structures, the abundance is greater in early structures for many of the heavier Period 4 and 5 elements (elements between the alkaline earths and the pnictogens have been omitted from these figures because some but not all periods have transition metals interpolated).

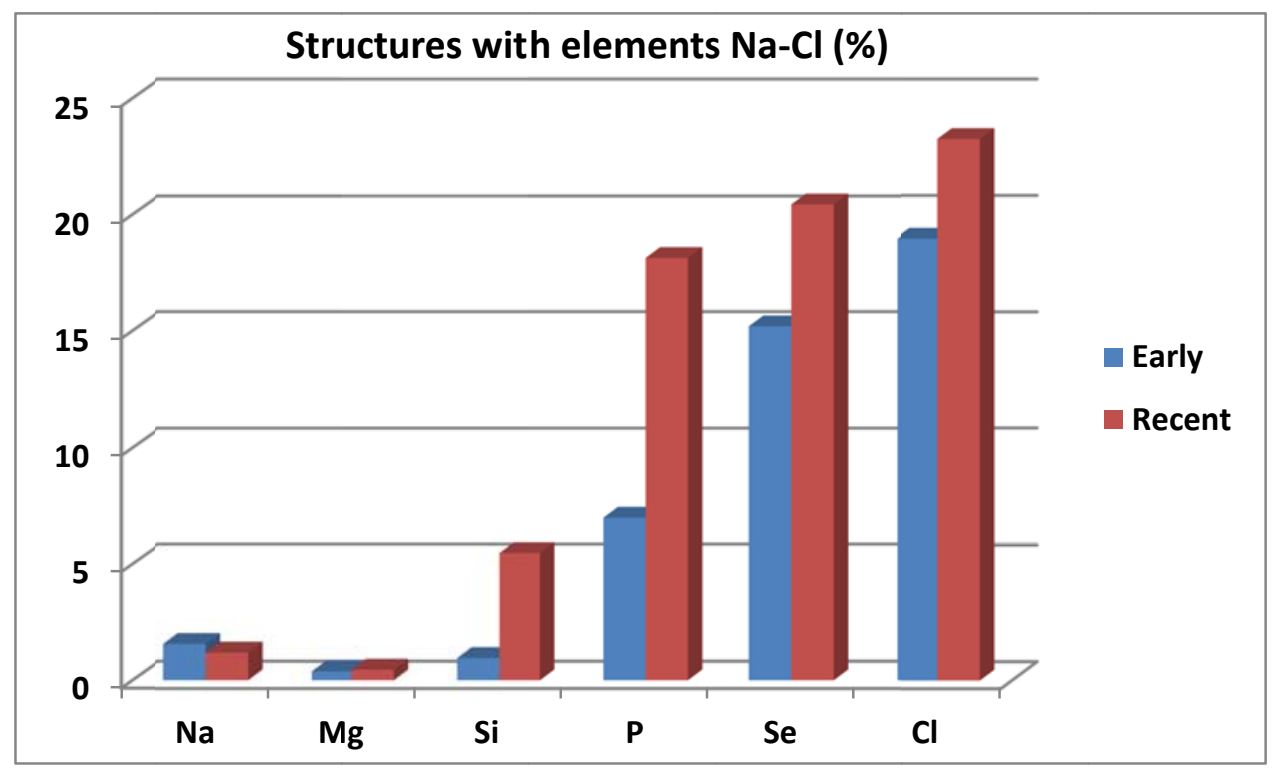

Figure 1. Percentages of crystal structures in the CSD containing designated elements in Period 3 of the Periodic Table during the early (1936-1939) and recent (1980-2013) periods

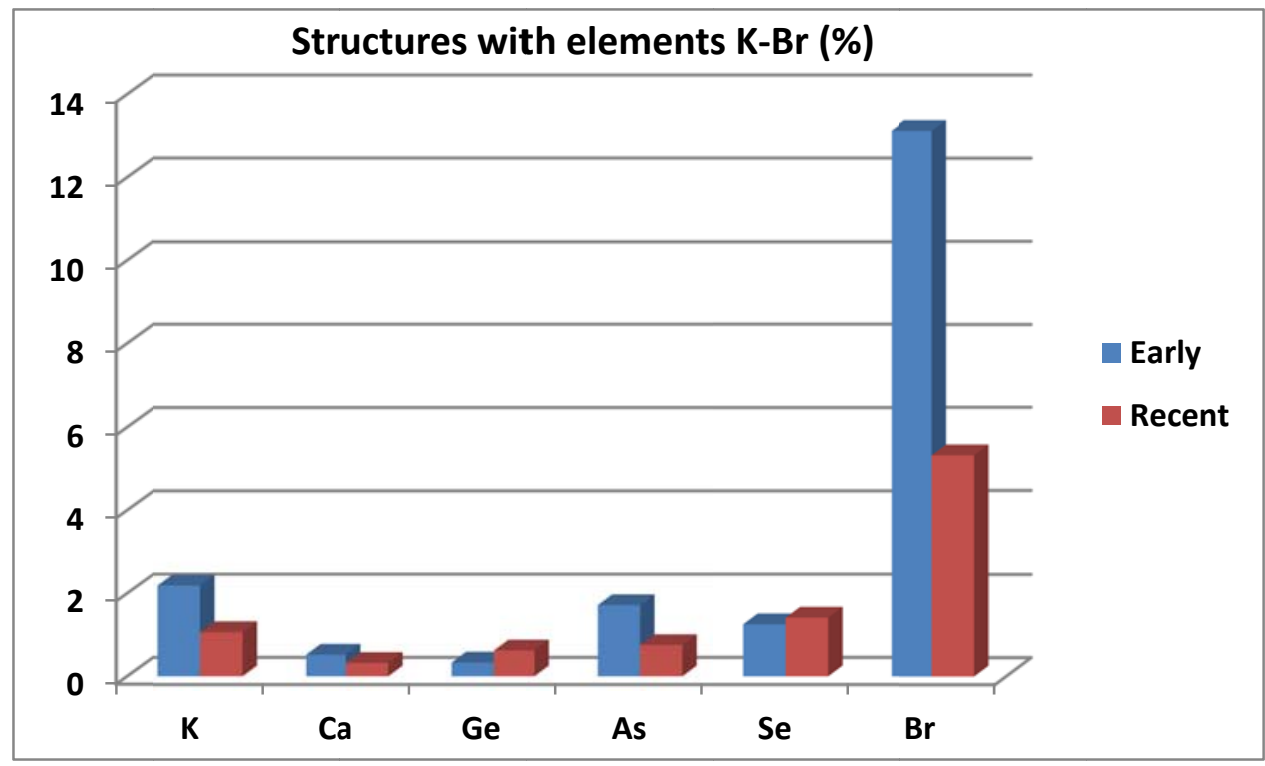

Figure 2. Percentages of crystal structures in the CSD containing designated elements in Period 4 of the Periodic Table during the early and recent periods 


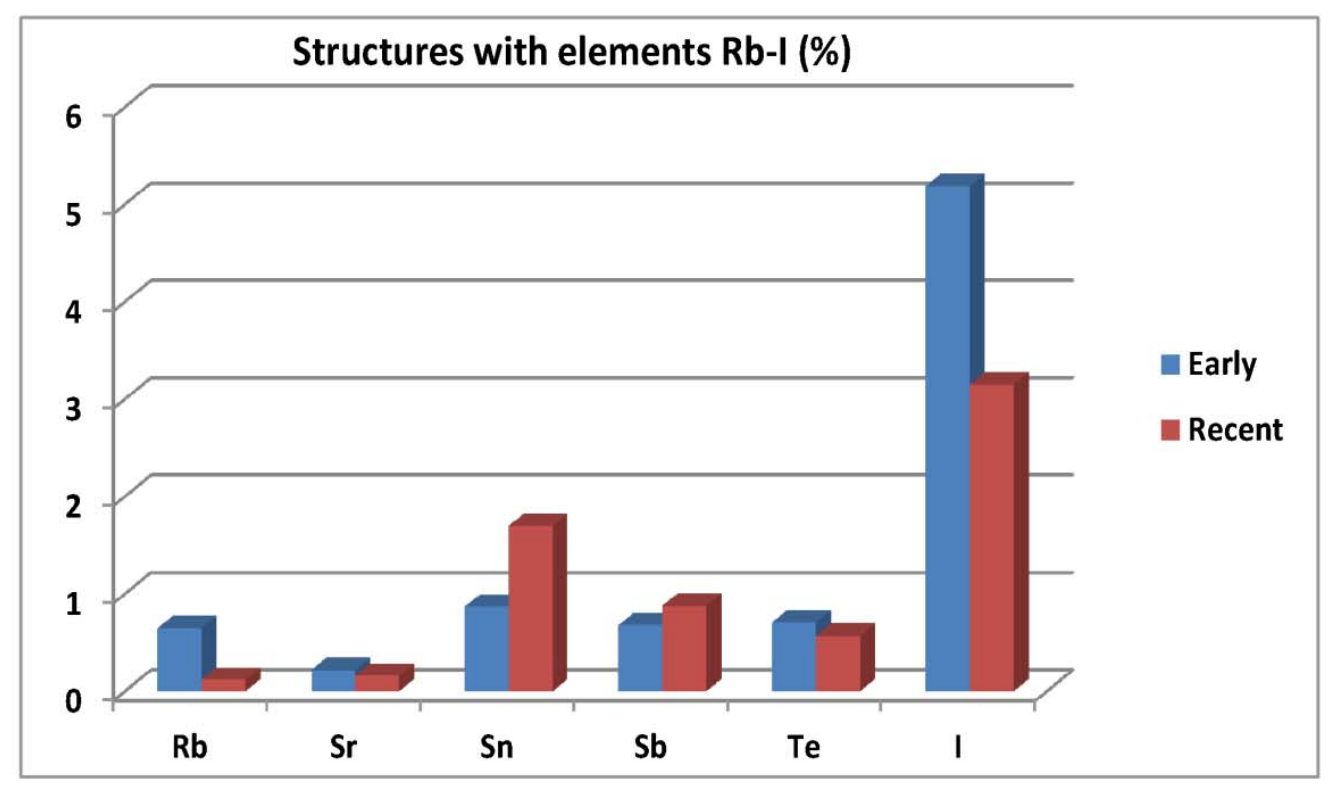

Figure 3. Percentages of crystal structures in the CSD containing designated element sin Period 5 of the Periodic Table during the early and recent periods

Because a particular atom may be of limited relevance to structure determination from Patterson maps by the heavy atom method if an even heavier atom is present, these searches were repeated for each element with the additional requirement that the element in question is the heaviest one in the structure. These results are shown in Table 2.

Table 2. Number of Cambridge Structural Database entries in which the indicated element is the heaviest one present, followed by the percentage of total entries, during 1936-1969 (above) and 1980-2013 (below). 


\begin{tabular}{|c|c|c|c|c|c|c|c|}
\hline $\mathrm{Na}$ & $\mathrm{Mg}$ & & $\mathrm{Al}$ & $\mathrm{Si}$ & $\mathrm{P}$ & $\mathrm{S}$ & $\mathrm{Cl}$ \\
\hline $\begin{array}{l}20 \\
0.54 \%\end{array}$ & $\begin{array}{l}4 \\
0.11 \%\end{array}$ & & $\begin{array}{l}9 \\
0.24 \%\end{array}$ & $\begin{array}{l}28 \\
0.76 \%\end{array}$ & $\begin{array}{l}77 \\
2.09 \%\end{array}$ & $\begin{array}{l}234 \\
6.36 \%\end{array}$ & $\begin{array}{l}349 \\
9.49 \%\end{array}$ \\
\hline $\begin{array}{l}1222 \\
0.19 \%\end{array}$ & $\begin{array}{l}1196 \\
0.19 \%\end{array}$ & & $\begin{array}{l}2441 \\
0.39 \%\end{array}$ & $\begin{array}{l}9417 \\
1.50 \%\end{array}$ & $\begin{array}{l}12694 \\
2.02 \%\end{array}$ & $\begin{array}{l}42366 \\
6.74 \%\end{array}$ & $\begin{array}{l}33873 \\
5.39 \%\end{array}$ \\
\hline $\mathrm{K}$ & $\mathrm{Ca}$ & Sc--Zn & $\mathrm{Ga}$ & $\mathrm{Ge}$ & As & $\mathrm{Se}$ & $\mathrm{Br}$ \\
\hline $\begin{array}{l}60 \\
1.63 \%\end{array}$ & $\begin{array}{l}15 \\
0.41 \%\end{array}$ & $\begin{array}{l}658 \\
17.90 \%\end{array}$ & $\begin{array}{l}2 \\
0.05 \%\end{array}$ & $\begin{array}{l}11 \\
0.30 \%\end{array}$ & $\begin{array}{l}38 \\
1.03 \%\end{array}$ & $\begin{array}{l}33 \\
0.90 \%\end{array}$ & $\begin{array}{l}450 \\
12.24 \%\end{array}$ \\
\hline $\begin{array}{l}2398 \\
0.38 \%\end{array}$ & $\begin{array}{l}1423 \\
0.23 \%\end{array}$ & $\begin{array}{l}154151 \\
24.53 \%\end{array}$ & $\begin{array}{l}2843 \\
0.45 \%\end{array}$ & $\begin{array}{l}2616 \\
0.42 \%\end{array}$ & $\begin{array}{l}2163 \\
0.34 \%\end{array}$ & $\begin{array}{l}4721 \\
0.75 \%\end{array}$ & $\begin{array}{l}23738 \\
3.78 \%\end{array}$ \\
\hline $\mathrm{Rb}$ & $\mathrm{Sr}$ & $\mathrm{Y}-\mathrm{Cd}$ & In & $\mathrm{Sn}$ & $\mathrm{Sb}$ & $\mathrm{Te}$ & I \\
\hline $\begin{array}{l}24 \\
0.65 \%\end{array}$ & $\begin{array}{l}8 \\
0.22 \%\end{array}$ & $\begin{array}{l}182 \\
4.95 \%\end{array}$ & $\begin{array}{l}2 \\
0.05 \%\end{array}$ & $\begin{array}{l}29 \\
0.79 \%\end{array}$ & $\begin{array}{l}24 \\
0.65 \%\end{array}$ & $\begin{array}{l}23 \\
0.63 \%\end{array}$ & $\begin{array}{l}181 \\
4.92 \%\end{array}$ \\
\hline $\begin{array}{l}600 \\
0.10 \%\end{array}$ & $\begin{array}{l}852 \\
0.14 \%\end{array}$ & $\begin{array}{l}86078 \\
13.70 \%\end{array}$ & $\begin{array}{l}2067 \\
0.33 \%\end{array}$ & $\begin{array}{l}9494 \\
1.51 \%\end{array}$ & $\begin{array}{l}4418 \\
0.70 \%\end{array}$ & $\begin{array}{l}2767 \\
0.44 \%\end{array}$ & $\begin{array}{l}15485 \\
2.46 \%\end{array}$ \\
\hline Cs & $\mathrm{Ba}$ & & & & & & \\
\hline $\begin{array}{l}13 \\
0.35 \%\end{array}$ & $\begin{array}{l}6 \\
0.16 \%\end{array}$ & & & & & & \\
\hline $\begin{array}{l}1022 \\
0.16 \%\end{array}$ & $\begin{array}{l}1406 \\
0.22 \%\end{array}$ & & & & & & \\
\hline
\end{tabular}




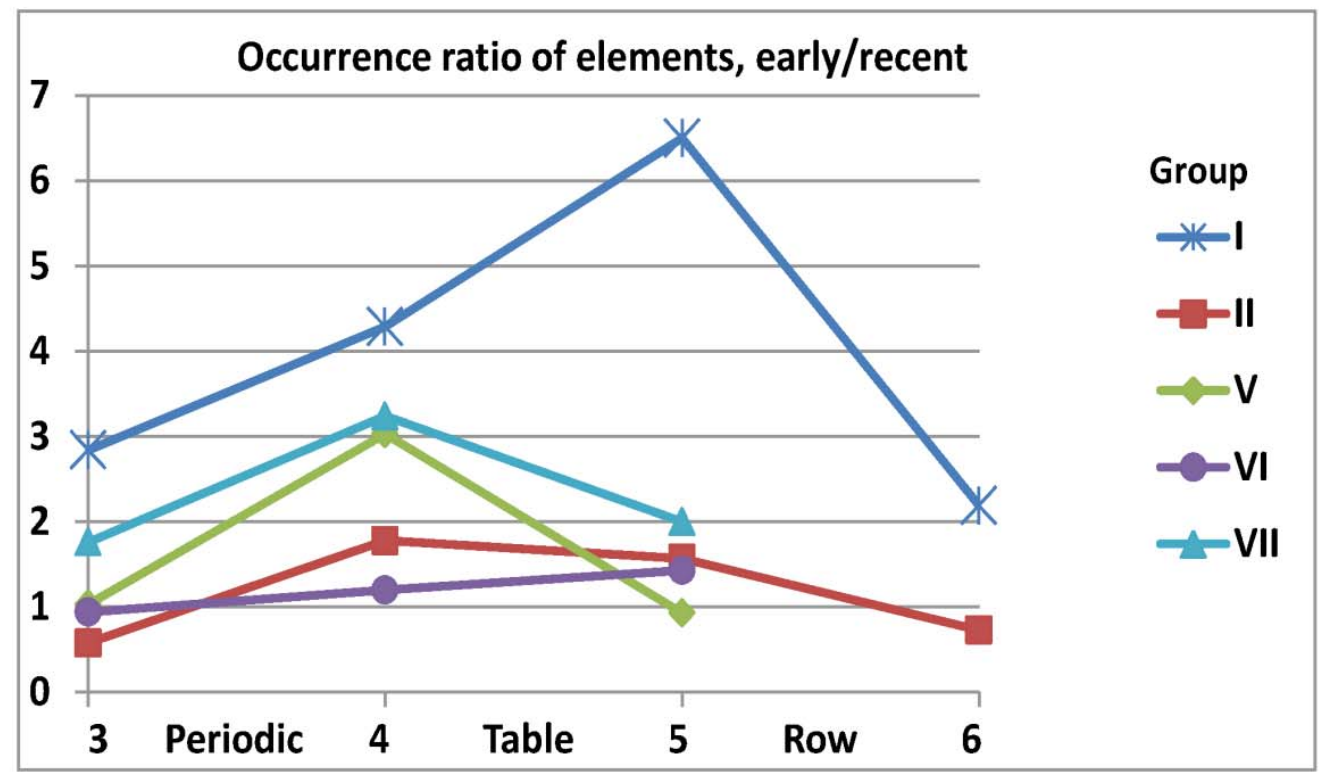

Figure 4. Plot of the ratio early : recent of percentage abundance in Table 2 against row of the Periodic Table for the alkali metals (Group I, IUPAC Group also 1), alkaline earths (II, 2), pnictogens (V, 15), chalcogens (VI, 16) and halogens (VII, 17).

Some important differences between the two classes have grown even more extreme. Figure 4 shows that departures above 3 occur for $\mathrm{K}, \mathrm{Rb}, \mathrm{As}$ and $\mathrm{Br}$. The presence of $\mathrm{Rb}^{+}$with the highest ratio and $\mathrm{Br}^{-}$with the greatest number of entries is not surprising since both have 36 electrons, which can be considered a "Goldilocks" number, not too few and not too many. As a representative structure in a centrosymmetric space group, we can consider a 1,4-disubstituted benzene ring with the first atom in each substituent being $\mathrm{C}$ and $\mathrm{N}$ respectively. The inversion operation will position a copy of this ring in a parallel orientation. Thus there will be 6 parallel C-C vectors from members of one ring to members of the other, augmented by two $\mathrm{C}-\mathrm{N}$ vectors between substituents. These vectors will sum to produce a peak of weight $(6 \times 6 \times 6)+(2 \times 6 \times 7)=300$. A vector between $\mathrm{K}^{+}$and $\mathrm{K}^{+}$or $\mathrm{Cl}^{-}$and $\mathrm{Cl}^{-}$would have relative height $(18 \times 18)=324$, which would not stand out clearly, although with patience it might be teased out. On the other hand, the relative height of vectors from $\mathrm{Rb}^{+}$to $\mathrm{Rb}^{+}$or $\mathrm{Br}^{-}$to $\mathrm{Br}^{-}$would be easily 
distinguishable at 1296. There would be no need to go up to $\mathrm{Cs}^{+}$or $\mathrm{I}^{-}$, which would yield even more distinguishable vectors but would so dominate the X-ray scattering that the remaining atoms in the structure would be difficult to locate accurately with the poor-quality data available at the time. Indeed, although the ratios for $\mathrm{Cs}^{+}$and $\mathrm{I}^{-}$both comfortably exceed 1 , they are much smaller than those for $\mathrm{Rb}^{+}$and $\mathrm{Br}^{-}$.

Another factor could be ease of preparation. Alkali metal salts of acids and halide salts of bases can be prepared by simple titration and often crystallized from water by slow evaporation. This could be a reason why the ratios are $>1$ even for elements as light as $\mathrm{Na}$ and $\mathrm{Cl}$. The same is not true for $\mathrm{Mg}$ or $\mathrm{S}$, and even $\mathrm{Sr}$ and $\mathrm{Se}$ with their appropriate number of electrons do not exceed a ratio of 2 . The exceptionally frequent occurrence of $\mathrm{Br}$ in early structures surely testifies to its chemical versatility. Besides the obvious hydrobromide salts, 332 of the 450 Br-containing structures in Table 2 are non-ionic. Br can be substituted into aliphatic and aromatic groups by standard reactions of organic chemistry, attached to a carborane, bound as a ligand to transition metal ions, incorporated into a complex with $\mathrm{Br}_{2}$ or a brominated solvent molecule or made into a cocrystal with a brominated coformer. Figure 5 classifies the majority of the halogen-containing structures in Table 2 as alkyl halides, aryl halides or halide salts. For bromine these three categories are almost equally represented, while for chlorine and even more strongly for iodine the ionic halide form is most common. 


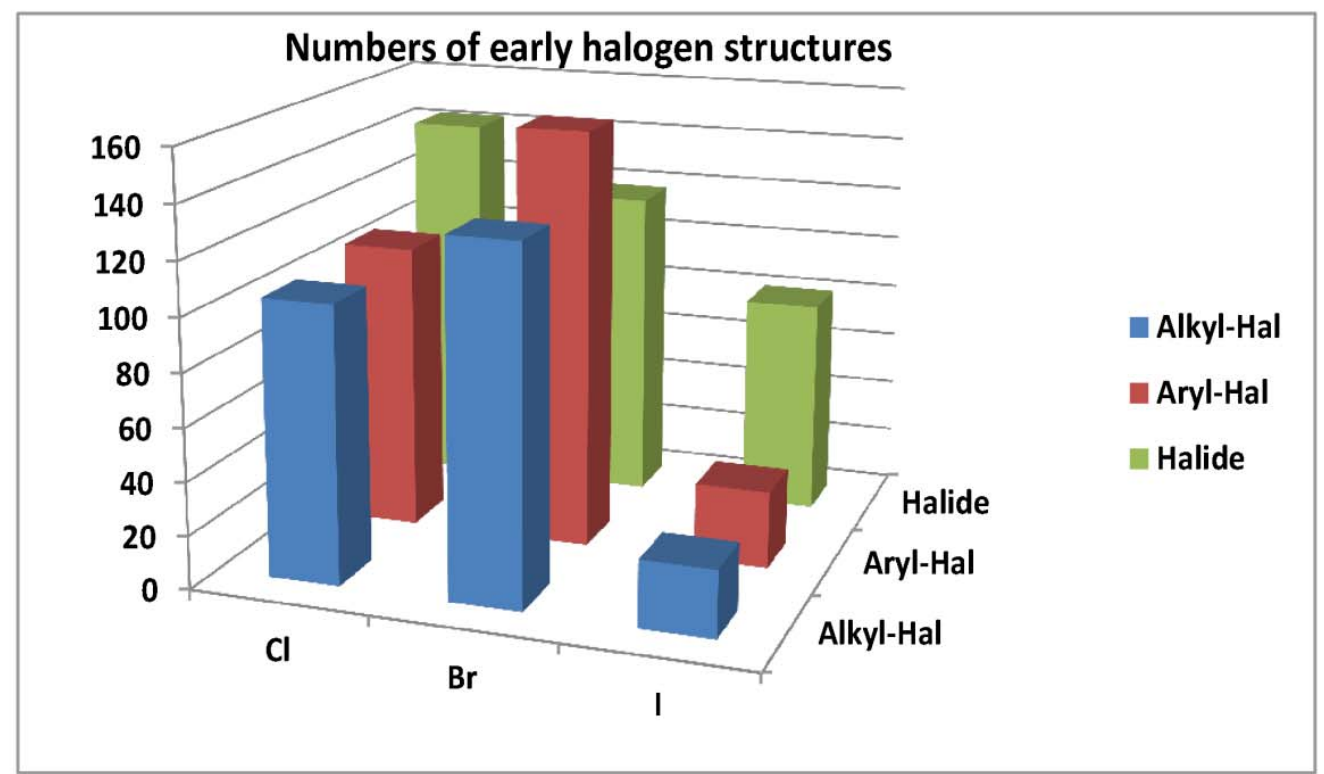

Figure 5. Number of early-period structures where a halogen is the heaviest element present in the form of an alkyl halide, an aryl halide or a halide ion.

It may appear surprising that, despite suitable atomic numbers for the heavy atom method, the transition metals from Sc to Zn occur somewhat less frequently in the early data than in the recent data, and those from $\mathrm{Y}$ to $\mathrm{Cd}$ occur much less frequently. This disparity may simply reflect later development of chemical interest. For instance, although one of the following three journals was the most prolific publisher of crystal structures [15] in each year between 1997 and 2004, Inorganic Chemistry only began publication in 1962, Journal of the Chemical Society Dalton Transactions in 1972 and Organometallics in 1982.

\subsection{Milestones and failures of the heavy atom method}


First, three examples will be presented, along with their CSD refcode and composition, of very challenging structural problems that were successfully solved by locating heavy atoms from a Patterson map and finding the remaining atoms in successive electron density maps phased by the contributions of atoms already known.

Cholesteryl iodide (CHOLSI, $\mathrm{C}_{27} \mathrm{H}_{45} \mathrm{I}$ ) [16]. Crystallizing in space group $\mathrm{P} 2{ }_{1}$, this was the first biologically significant molecule to undergo structure determination by the heavy atom method. The vector between the two iodine atoms in the unit cell was identified, enabling positions for these atoms to be assigned within the unit cell. However, a spurious inversion centre appeared between them, and therefore an electron density map calculated with phases based only on these iodine atoms revealed not just the correct structure but also, superimposed upon it, a spurious mirror image. Applying their knowledge of expected geometry, Harry Carlisle and Dorothy Crowfoot (Hodgkin) were able to select the correct atomic positions.

Vitamin B12 carboxylic acid degradation product [VITCAC, $\mathrm{C}_{46} \mathrm{H}_{58} \mathrm{ClCoN}_{6} \mathrm{O}_{13} \cdot \mathrm{C}_{3} \mathrm{H}_{6} \mathrm{O} .2\left(\mathrm{H}_{2} \mathrm{O}\right)$ ] [17]. Determination of this structure by Dorothy Hodgkin and her colleagues was a remarkable application of the heavy atom method. The vitamin molecule had been simplified by replacement with $\mathrm{Cl}$ of the dimethylbenzamidazole group at one coordination site of Co and pruning of side groups on the corrin ring system, and the space group P $2{ }_{1} 2{ }_{1} 2_{1}$ with its three Harker planes was beneficial; but it still represented a formidable challenge. Knowledge of its structure provided essential information for an understanding of the stereochemistry of the vitamin. Initially only the Co atom was located from Patterson projection maps, but an electron density map calculated with Co phases revealed more atoms. Successive calculation of electron density maps using phases for structure factors based on increased numbers of atoms eventually yielded the entire structure and overcame perceived disorder of one side chain. A similar procedure was subsequently used to solve the even more complicated structure, displayed in Figure 6, of the entire vitamin B12 coenzyme 5'-deoxyadenosylcobalamin, DADCBL, [ $\left.\mathrm{C}_{72} \mathrm{H}_{100} \mathrm{CoN}_{18} \mathrm{O}_{17} \mathrm{P} .17\left(\mathrm{H}_{2} \mathrm{O}\right)\right]$ 
[18]. In common with the simpler degradation product, the space group of the coenzyme is $\mathrm{P} 2{ }_{1} 2{ }_{1} 2$; but its unit cell dimensions ( $a=27.93, b=21.73, c=15.34 \AA$ ) bear no obvious relation to those for the degradation product $(a=24.58, b=15.52, c=$ $13.32 \AA$ Á). Even though each cobalt atom is accompanied by well over 100 other nonhydrogen atoms in the asymmetric unit, the author reported that 'the cobalt atoms were easily located from the Patterson synthesis.' It can be seen from Figure 6 that these atoms are perilously close to special positions on unit cell edges (fractional atomic coordinates $0.0482,0.1819,0.0183)$, but not so close that pseudosymmetry would preclude structure completion.

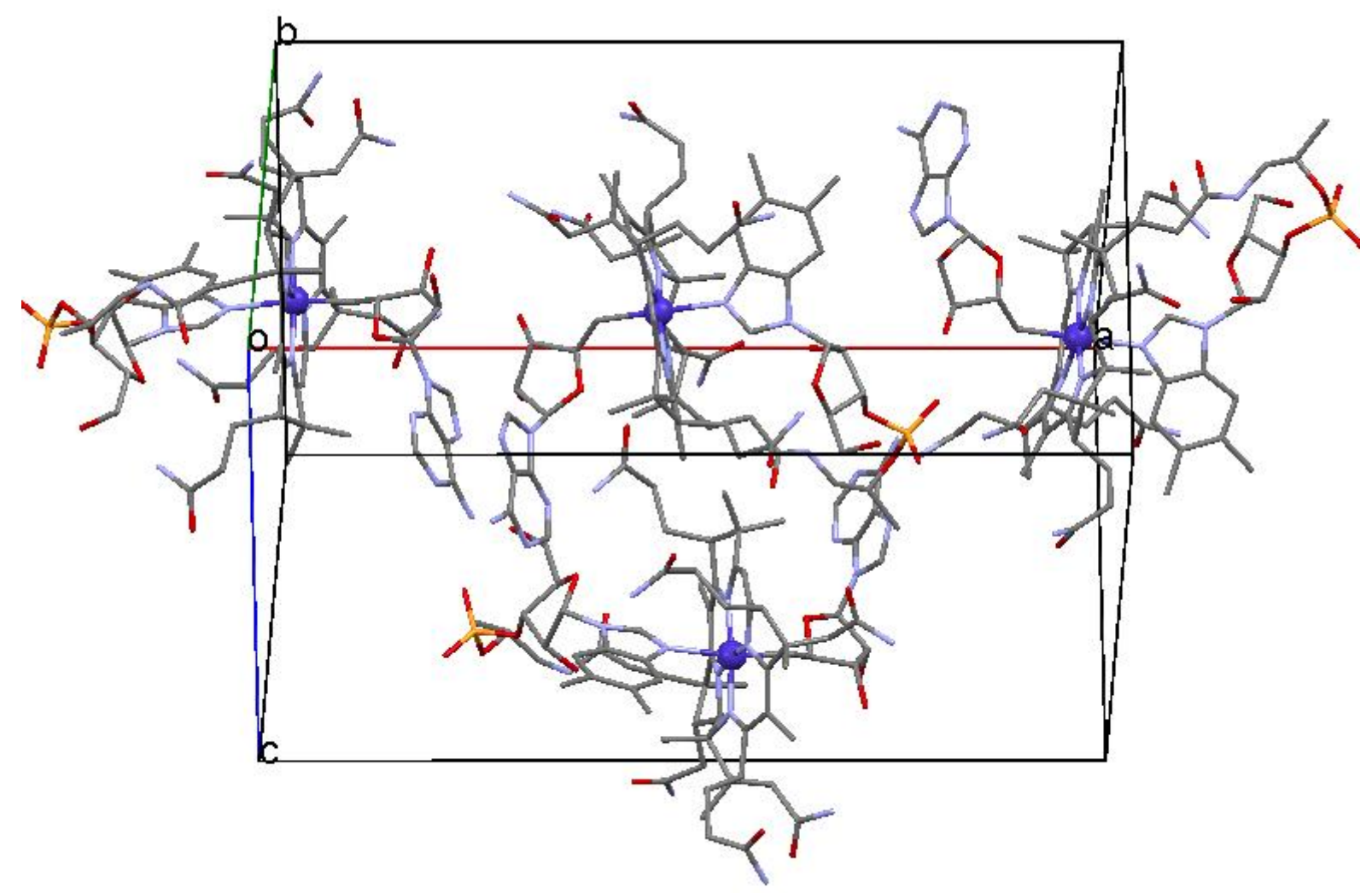

Figure 6. Packing diagram for vitamin B12 coenzyme drawn with Mercury [31]. Cobalt atoms are shown as spheres, and other non-hydrogen atoms as capped sticks. Hydrogen atom positions were not determined; and, to preserve clarity, they have not been added to the drawing. 
Withaferin A acetate $p$-bromoacetate [WIHABB, $\mathrm{C}_{37} \mathrm{H}_{43} \mathrm{BrO}_{8} .0 .5\left(\mathrm{C}_{4} \mathrm{H}_{8} \mathrm{O}_{2}\right)$ ] [19]. During the period under discussion this was the molecule with the greatest number of light atoms for one bromine atom to be determined by means of the heavy atom method. Helpfully, the space group was $\mathrm{P} 22_{1} 2_{1} 2_{1}$, but an added complication was that Z' $=2$. The Patterson map enabled the bromine atoms to be located; and subsequent electron density maps revealed the $\mathrm{C}$ and $\mathrm{O}$ atoms of the molecule of interest, although ethyl acetate solvent of crystallisation was only ever diffusely visible.

Lest these three highly successful applications of the heavy atom method might convey an impression of guaranteed success, two structures are presented next in which the heavy atom could be located from Patterson maps but the rest of the structure remained obscure until additional methodology was deployed.

Rubidium benzylpenicillin (HIDJEM, $\mathrm{C}_{16} \mathrm{H}_{17} \mathrm{~N}_{2} \mathrm{O}_{4} \mathrm{~S}^{-} . \mathrm{Rb}^{+}$)[20,21]. After the successful structure determination of cholesteryl iodide by Dorothy Hodgkin's group, this structure appeared to be an easier proposition in view of the helpful space group $\mathrm{P} 2{ }_{1} 2{ }_{1}{ }_{1}$, the smaller number of atoms in the asymmetric unit and the experience amassed by this group in the interpretation of Patterson maps. Although Figure 7 shows a relatively sparse population of atoms that need to be located, it also shows that $\mathrm{Rb}$ atoms are located exactly on special positions (fractional coordinates $0.358,0.550$, 0.000). This unfortunate positioning meant that once they had been found from a vector map, phases based on these atoms did not yield an electron density map with interpretable positions for other atoms. After a lot of effort the structure was completed by the traditional trial-and-error approach. Subsequently the data were re-examined by Robertson, who demonstrated that application of the newly developed vector convergence method [22] to the Patterson map would produce the structure [23], albeit with the benefit of knowing the answer in advance. This procedure uses the 4 equivalent positions for the heavy $\mathrm{Rb}$ atom as origin points for 4 copies of the Patterson map. Points on which the vectors converge should represent the remaining atomic positions. The positioning of $\mathrm{Rb}$ atoms at $z=0$ and $z=1 / 2$ left an ambiguity; to obtain a clear convergence map it was deemed necessary also to pick out the $\mathrm{S}$ atoms, which lie 
in general positions. As a more practical procedure, electron density maps calculated with $\mathrm{Rb}$ and $\mathrm{S}$ phases were used to exclude unlikely locations for other atoms.

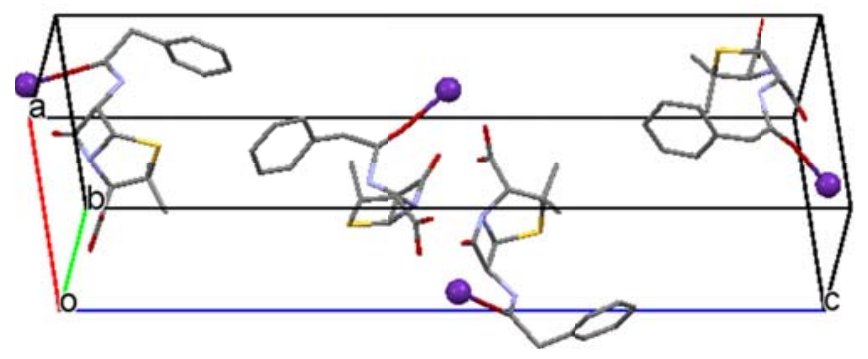

Figure 7. Packing diagram for rubidium benzylpenicillin drawn with Mercury [31]. Rubidium atoms are shown as spheres, and other non-hydrogen atoms as capped sticks. Hydrogen atom positions were not determined; and, for comparability with Figure 6, they have not been added to the drawing.

Leurocristine methiodide (LCRMIH10, $\mathrm{C}_{47} \mathrm{H}_{59} \mathrm{O}_{10} \mathrm{~N}_{4}{ }^{+} . \mathrm{I}^{-} .2 \mathrm{H}_{2} \mathrm{O}$ ) [24,25]. The space group P2 1 was not the most favourable for the provision of Harker sections; and because crystals decomposed in the X-ray beam, data had to be collected from 5 different crystals and merged. Nevertheless, iodine atoms were located from the Patterson map. Unfortunately, phases based on these atoms were not adlequate to reveal more atoms in an electron density map. Despite the problems associated with crystal decay, intensity data collected with $\mathrm{CuK} \alpha$ radiation achieved sufficient accuracy to show the effect of anomalous scattering. These data were ingeniously used in tandem with the Patterson function to obtain a solution. Two approaches were employed, both devised in research groups that are more commonly remembered for other achievements but had been attracted into this field: R. Pepinsky's group at Pennsylvania State University, developers of the XRAC analogue computer, and G.N. Ramachandran's group at Madras University, authors of the protein conformation plot. 
Since only the iodine atoms gave appreciable anomalous scattering, and since they were much heavier than any other atoms in the structure, vectors between light atoms could be neglected. Taking the scattering factor as $f=f^{\prime}+$ if $f^{\prime}$, the modified Patterson functions $[26,27] P_{c}(\mathrm{u})$ and $P_{s}(\mathrm{u})$ expressed as

$P_{c}(u, v, w)=\sum_{h k l}\left|F_{h k l}\right|^{2} \cos 2 \pi(h u+k v+l w)$

and

$P_{s}(u, v, w)=\sum_{h k l}\left|F_{h k l}\right|^{2} \sin 2 \pi(h u+k v+l w)$

were mapped. At $\mathrm{u}=\mathrm{r}_{i}-\mathrm{r}_{j}$ the $P_{c}(\mathrm{u})$ function has peaks of height $f_{i}^{\prime} f_{j}^{\prime}+f_{j}$ ' $f_{i}$ ' at positions of the usual centrosymmetric Patterson function, and $P_{s}(\mathrm{u})$ provides peaks of height $f_{i}$ ' $f_{j}$ " $-f_{j}$ ' $f_{i}$ " with a centre of antisymmetry. Added together with an appropriate weighting factor $b$, the sum function $P_{c}(\mathrm{u})+b P_{s}(\mathrm{u})$ [28] should contain only positive peaks at $\mathrm{u}=\mathrm{r}_{i}-\mathrm{r}_{j}$ with the absolute configuration preserved. Alternatively, the authors applied a method $[29,30]$ devised to use the anomalous scattering to break the false centrosymmetry of a map calculated with iodine phases alone. Although both methods yielded maps with so many false peaks that the correct positions for light atoms were obscured, collating the peaks present in both maps revealed 37 correct atomic positions, sufficient to complete the structure.

\subsection{Conclusion}

The Patterson function, as implemented in the heavy atom method, opened the way for the structure determination of small molecules of greater complexity than ever before and made it possible to answer some important biochemical questions. Because failures are unlikely to have been published, it is now impossible to know how many attempts at structure determination by this method either failed to locate the heavy atom or stalled once it had been found. Nevertheless, enough successful determinations were reported to lead to a sizeable excess of heavy atoms in the CSD during the period when Patterson methods were dominant. 


\section{References}

[1] Bragg WL. The Structure of Some Crystals as Indicated by their Diffraction of Xrays. Proc. Roy. Soc. Lond. A. 1913; 89: 248-277.

[2] Lonsdale K. The Structure of the Benzene Ring in Hexamethylbenzene. Proc. Roy. Soc. Lond. A. 1929; 123: 494-515.

[3] Marsh RE, Shoemaker DP. Obituary. Arthur Lindo Patterson 1902-1966. [Internet] Buffalo, NY: International Union of Crystallography; 1967 [cited June 17, 2014]. Available from: http://journals.iucr.org/q/issues/1967/05/00/a05543/a05543.pdf

[4] Patterson AL. A Fourier Series Method for the Determination of the Components of Interatomic Distances in Crystals. Phys. Rev. 1934; 46: 372-376.

[5] West J. A Quantitative X-ray Analysis of the Structure of Potassium Dihydrogen Phosphate $\left(\mathrm{KH}_{2} \mathrm{PO}_{4}\right)$. Z. Krist. 1930; 74: 306-355.

[6] Lonsdale K. An X-Ray Analysis of the Structure of Hexachlorobenzene, Using the Fourier Method. Proc. Roy. Soc. Lond. A. 1931; 133: 536-552.

[7] Harker D. Review in J. Appl. Cryst. 1973; 6: 252, of Bijvoet JM, Burgers WG, Hägg G, Editors. Early Papers on Diffraction of X-rays by Crystals. Utrecht: Oosthoek; 1972.

[8] Patterson A.L. A Direct Method for the Determination of the Components of Interatomic Distances in Crystals. Z. Krist. 1935; 90: 517-542.

[9] Harker D. The Application of the Three-Dimensional Patterson Method and the Crystal Structures of Proustite, $\mathrm{Ag}_{3} \mathrm{AsS}_{3}$, and Pyrargyrite, $\mathrm{Ag}_{3} \mathrm{SbS}_{3}$. J. Chem. Phys. 1936; 4: 381-390. 
[10] Buerger M J. A New Approach to Crystal-Structure Analysis. Acta Crystallogr. 1951; 4: 531-544.

[11] Wrinch DM. The Geometry of Discrete Vector Maps. Phil. Mag. 1939; 27: 98122.

[12] Wrinch DM. Vector Maps of Finite and Periodic Points Sets. Phil. Mag. 1939; 27: 490-507.

[13] Allen FH. The Cambridge Structural Database: a Quarter of a Million Crystal Structures and Rising. Acta Crystallogr. B. 2002; 58: 380-388.

[14] Germain G, Main P, Woolfson MM. On the Application of Phase Relationships to Complex Structures. II. Getting a Good Start. Acta Crystallogr. 1970; 26: 274-285.

[15] Sarjeant AA. High Impact Crystallography? - A Statistical Analysis of Crystal Structures Reported in the CSD (1997-2012). Abstract 1.2.4.21. Poster session presented at American Crystallographic Association Annual Meeting; 2014 May 25; Albuquerque, NM [cited 2014 June 14]. Available from: http://www.amercrystalassn.org/app/session/100169?page $=2$

[16] Carlisle CJ, Crowfoot D. The Crystal Structure of Cholesteryl Iodide. Proc. R. Soc. Lond. A. 1945; 184: 64-83.

[17] Hodgkin DC, Pickworth J, Robertson JH, Prosen RJ, Sparks RA, Trueblood KN, Vos A. The Structure of Vitamin B12. II. The Crystal Structure of a Hexacarboxylic Acid Obtained by the Degradation of Vitamin B12. Proc. Roy. Soc. Lond. A. 1959; 251: 306-352. 
[18] Lenhert PG. The Structure of Vitamin B12. VII. The X-ray Analysis of the Vitamin B12 Coenzyme. Proc. R. Soc. Lond. A. 1968; 303: 45-84.

[19] McPhail AT, Sim GA. Molecular Conformations. Part V1. The Structure of Withaferin A : X-Ray Analysis of Withaferin A Acetate p-Bromobenzoate. J. Chem. Soc. (B). 1968: 962-972.

[20] Crowfoot D, Bunn C.W, Rogers-Low BW, Turner-Jones A. The X -ray Crystallographic Investigation of the Structure of Penicillin. In: Clarke HT, Johnson J R, Robinson R, editors. Chemistry of Penicillin. Oxford: Oxford University Press; 1949. p. $310-367$.

[21] Ferry G. Dorothy Hodgkin: A Life. London: Granta Books; 1998. p. 204-205, 208212.

[22] Beevers CA, Robertson JH. Interpretation of the Patterson synthesis. Acta Crystallogr. 1950; 3: 164-164.

[23] Robertson JH. Interpretation of the Patterson synthesis: rubidium benzyl penicillin. Acta Crystallogr. 1951; 4: 63-66.

[24] Moncrief JW, Lipscomb WN. Structures of Leurocristine (Vincristine) and Vincaleukoblastine. X-Ray Analysis of Leurocristine Methiodide. J. Amer. Chem. Soc. 1965: 87: 4963-4964.

[25] Moncrief JW, Lipscomb WN. Structure of Leurocristine Methiodide Dihydrate by Anomalous Scattering Methods; Relation to Leurocristine (Vincristine) and Vincaleukoblastine (Vinblastine). Acta Crystallogr. 1966; 21: 322-331.

[26] Okaya Y, Saito Y, Pepinsky R. New Method in X-Ray Crystal Structure Determination Involving the Use of Anomalous Dispersion. Phys. Rev. 1955; 98: 18571858. 
[27] Pepinsky R, Okaya Y. Determination of Crystal Structures by Means of Anomalously Scattered X-rays. Proc. Nat. Acad. Sci. Wash. 1956: 42: 286-292.

[28] Lipscomb W.N. Vector Convergence in the Noncentrosymmetric $|F|^{2}$ Series. $J$. Chem. Phys. 1957; 26: 713-714.

[29] Peerdeman AF, Bijvoet JM. The Indexing of Reflexions in Investigations Involving the Use of the Anomalous Scattering Effect. Acta Crystallogr. 1956; 9: 1012-1015.

[30) Ramachandran GM, Raman S. A New Method for the Structure Analysis of Noncentrosymmetric Crystals. Curr. Sci. 1956; 25: 348-351.

[31] Macrae CF, Bruno IJ, Chisholm JA, Edgington PR, McCabe P, Pidcock E, Rodriguez-Monge L, Taylor R, van de Streek J, Wood PA. Mercury CSD 2.0 - New Features for the Visualization and Investigation of Crystal Structures. J. Appl. Cryst. 2008; 41: 466-470. 